\title{
ARMAZENAMENTO DE SEMENTES DE ARROZ E MILHO EM DIFERENTES EMBALAGENS E LOCALIDADES PAULISTAS ( ${ }^{1}$ )
}

\author{
LUIZ FERNANDES RAZERA $\left({ }^{2,5}\right)$, ANTONIO AUGUSTO DO LAGO $\left({ }^{2,5}\right)$, \\ JOCELY ANDREUCCETTI MAEDA $\left({ }^{2}\right)$, EDUARDO ZINK $\left({ }^{3}\right)$, \\ GENTIL GODOY JÚNIOR $\left({ }^{4}\right)$ E ROMEU DE TELLA $\left({ }^{2}\right)$
}

\section{RESUMO}

Acondicionaram-se sementes de arroz 'IAC 1246' (Oryza sativa L.) e milho 'Hmd 7974' (Zea mays L.) em embalagens permeáveis ao vapor de água - pano, papel, plástico trançado $5 \times 5$ e 5 × 6 - e na relativamente impermeável - plástico liso, de 0,25 mm de espessura. Mantiveram-nas em condiçöes nāo controladas de armäzém nas localidades de Campinas e Ubatuba, testando-as quanto à umidade, germinação e vigor a cada trimestre, por 36 meses. As sementes armazenadas em Ubatuba deterioraram-se mais rapidamente, sobretudo quando acondicionadas nas embalagens permeáveis. Em Campinas, as sementes de arroz embaladas em sacos de pano mantiveram germinação acimá de $80 \%$ até os quinze meses, enquanto aquelas de Ubatuba o fizeram somente até os seis meses. $\mathrm{O}$ acondicionamento em saco de plástico liso foi bastante vantajoso, principalmente em Ubatuba, onde, aos 15 meses, a germinação das sementes de milho foi nula quando mantidas nas outras embalagens, e de $97,5 \%$ quando no saco plástico liso. As embalagens de pano,

(1) Recebido para publicação em 20 de fevereiro de 1986.

(2) Seçāo de Sementes, Instituto Agronômico (IAC), Caixa Postal 28, 13001 Campinas (SP).

(3) Divisāo de Biologia Fitotécnica, IAC.

( ${ }^{4}$ ) Estação Experimental de Ubatuba, IAC.

(5) Com bolsa de suplementação do CNPq. 
papel, plástico trançado $5 \times 5$ e $5 \times 6$ foram semelhantes entre si na manutenção da germinação e do vigor das sementes. Os resultados obtidos salientaram a grande dificuldade ou mesmo impossibilidade do armazenamento de sementes em áreas quentes e ámidas, como Ubatuba, a menos que haja controle da temperatura e umidade relativa do ambiente do armazém, ou mediante secagem das sementes ate níveis relativamente baixos de umidade (10$-11 \%$ ou menos) seguida de acondicionamento em embalagem que ofereça resistência à troca de umidade. As embalagens permeáveis ao vapor de água mostraram-se bastante práticas para o armazenamento em regiōes de clima mais favorável à manutenção da viabilidade das sementes.

Termos de indexação: arroz, Oryza sativa L., milho, Zea mays L., sementes, armazenamento, embalagens.

\section{INTRODUÇÃo}

Armazenamento adequado, com instalações e técnicas apropriadas, é um componente essencial em um programa de produção e comercialização de sementes. A preservação da viabilidade e do vigor desse importante insumo agricola desde a colheita até o plantio protege o investimento, o lucro e a reputação do produtor, permitindo que o usuário tenha à sua disposição sementes de alta qualidade fisiológica (DELOUCHE, 1968).

A velocidade de deterioração das sementes é influenciada por fatores genéticos, formas de manipulação e condiçōes de armazenamento (DELOUCHE et alii, 1973; JUSTICE \& BASS, 1978). Dessas condições, as mais importantes para a manutenção da viabilidade e do vigor das sementes são temperatura e umidade relativa do ambiente do armazém (HARRINGTON, 1972), sendo este último fator o de maior influência (HELMER, 1965; HARRINGTON, 1973).

Segundo DELOUCHE et alii (1973), a umidade relativa afeta a qualidade fisiológica das sementes de duas maneiras: (a) seu conteúdo de umidade é função da umidade relativa ambiente e (b) a infestação, o crescimento e a reprodução de fungos e insetos são fortemente influenciados pela umidade relativa do microambiente na massa de sementes.

Embora as condições ambientes do armazém possam ser artificialmente controladas, o custo para tał controle em grandes áreas de armazenamento não é geralmente econômico, o que faz com que quase todo o volume de sementes produzido no Brasil seja armazenado a temperatura e umidade relativa ambientes.

As embalagens utilizadas no acondicionamento de sementes também podem ter efeitos na sua longevidade. Tais embalagens podem ser perfeitamente permeáveis, como sacos de pano, ou relativamente impermeáveis, como sacos plásticos (HAGGERTY JR., 1960; DANIELSON, 1962; HARRINGTON, 1973; 
JUSTICE \& BASS, 1978). Estes últimos podem ser adequados para sementes que, após convenientemente secas, precisam ser armazenadas em regiōes úmidas, uma vez que oferecem resistência à passagem de vapor de água, evitando que a semente se reidrate até niveis altos e se deteriore rapidamente (HARRINGTON, 1973; DELOUCHE, 1981).

DELOUCHE (1981), observando as necessidades de pesquisa aplicada em sementes no Brasil, salientou a importância de estudos que determinem o período em que as sementes das espécies cultivadas mantém um nivel de qualidade aceitável sob condições não controladas de armazém nas diversas áreas geográficas do nosso país.

As sementes de arroz e milho, mesmo nāo tendo armazenabilidade tão problemática quando comparadas com, por exemplo, as de amendoim e soja, necessitam dos estudos mencionados, principalmente por prazos médios a longos.

FONSECA et alii (1979), pesquisando longevidade de sementes de arroz sob condiçōes comuns de armazém na região de Sete Lagoas, MG, verificaram que elas não sofreram prejuízos em sua qualidade fisiológica por 16 meses; a partir daí, a germinação decresceu, reduzindo-se a $0 \%$ aos 40 meses.

TOSELLO et alii (1968) observaram que sementes de arroz mantidas em condições normais de armazém em Campinas conservaram-se bem por 26 meses, quando apresentaram ainda $75 \%$ de germinação.

Sementes de milho 'Hmd 6999' e 'Asteca', armazenadas no Centro Experimental de Campinas, em condições de laboratório e tratadas com inseticidas contra o carunchamento, mantiveram germinação acima de $80 \%$ após doze meses (BACCHI \& ZINK, 1962).

MAEDA et alii (1979), estudando a longevidade de sementes de milho 'Hmd 6999-B' produzidas em solos com diferentes niveis de adubação mineral NPK, verificaram que, em todos os tratamentos, a germinação daquelas protegidas contra insetos manteve-se acima de $90 \%$ após 25 meses de armazenamento em condiçóes de laboratório no Centro Experimental de Campinas.

Resultados de MORA \& ECHANDI (1976), na Costa Rica, revelaram que é perfeitamente possivel conservar sementes de arroz e milho por pelo menos seis meses a $20^{\circ} \mathrm{C}$, mesmo com conteúdos de umidade relativamente altos, como $13,4 \%$. Eles acrescentaram que a mesma boa conservação pode ser obtida a temperaturas mais altas $\left(30-35^{\circ} \mathrm{C}\right)$, desde que a umidade da semente seja suficientemente baixa $(10,0 \%)$.

No presente trabalho, estudaram-se aspectos fisiológicos da deterioração de sementes de arroz e milho, acondicionadas em diferentes tipos de embalagens e armazenadas em condições comuns nas localidades de Campinas e Ubatuba por 36 meses. 


\section{MATERIAL E MÉTODOS}

As sementes utilizadas neste trabalho foram as de arroz (Oryza sativa L.) do cultivar IAC 1246 e do milho híbrido 'Hmd 7974' (Zea mays L.), produzidas em campos de certificação da Coordenadoria de Assistência Técnica Integral (Secretaria de Agricultura e Abastecimento do Estado de São Paulo) no ano agricola 1974/75.

Dez sacas de $40 \mathrm{~kg}$ de cada espécie foram retiradas de seus lotes originais e acondicionadas em cinco diferentes tipos de embalagens com $40 \mathrm{~kg}$ cada uma: (a) saco de pano constituído de fios de algodão trançado; (b) saco de papel multifolhado, com paredes de cinco folhas; (c) saco de plástico liso de polietileno, com paredes de $0,25 \mathrm{~mm}$ de espessura; (d) saco de plástico trançado $5 \times 5$ (cinco fitas de polipropileno no urdume e seis na trama, por centímetro quadrado); (e)saco de plástico trançado $5 \times 6$ do mesmo material anterior.

A seguir, uma das duas sacas relativas a cada espécie e embalagem foi armazenada no Centro Experimental de Campinas e a outra, na Estação Experimental de Ubatuba, em condições comuns de armazém de alvenaria, sujeitas, portanto, às variaçōes de temperatura e umidade relativa ambientes das duas localidades. As médias mensais desses dois fatores climáticos nelas observadas durante a realização do experimento (novembro de 75 a outubro de 78 ) estão no quadro 1 (RESENHAS, 1975/76, 1977/78 e 1979, e registros da Seção de Climatologia do (AC).

A cada trimestre, por 36 meses, uma amostra representativa de cada tratamento foi retirada, com uma quantidade de sementes suficiente para a execução de testes de umidade, germinação e vigor.

As determinaçōes do teor de umidade foram feitas em estufa elétrica a $105^{\circ} \mathrm{C}$ por 24 horas, utilizando-se duas repetições de aproximadamente $50 \mathrm{~g}$ cada uma, sendo os resultados calculados com base no peso úmido (BRASIL, 1980).

Os testes de germinação para cada espécie foram realizados com quatro repetiçōes de 50 sementes cada uma, sendo que as condiçōes de substrato, temperatura, duração do teste e avaliação de plântulas seguiram as Regras para Análise de Sementes (BRASIL, 1980).

Efetuaram-se os testes de vigor (envelhecimento acelerado) de acordo com equipamentos e técnicas descritos por DELOUCHE \& BASKIN (1973). Mantiveram-se as sementes de ambas as espécies em câmara especial a $42^{\circ} \mathrm{C} e$ $100 \%$ U.R. por sete dias, submetendo-as então ao teste normal de germinação (BRASIL, 1980).

A análise estatística dos dados de germinação e vigor, feita por períodos, constou de esquema inteiramente casualizado, com quatro repetiçōes, sendo as porcentagens previamente transformadas em arco seno $\sqrt{\% / 100}$. 


\section{RESULTADOS E DISCUSSĀO}

No quadro 2, acham-se os dados de conteúdo de umidade das sementes nos diversos períodos de armazenamento. Para ambas as espécies, as sementes nas diversas embalagens, com exceção da de plástico liso, atingiram o equilíbrio higroscópico com a umidade relativa ambiente aos três meses em Campinas e entre os seis e nove meses em Ubatuba. Essa maior demora para atingir o equilíbrio higroscópico na última região deveu-se à maior quantidade de vapor de água que as sementes absorveram, dada a umidade relativa mais alta prevalecente na área (Quadro 1). Este fato fez com que os conteúdos de umidade das sementes das duas espécies atingissem valores mais altos quando armazenadas em Ubatuba que, após equilíbrio, estiveram ao redor de $14,7 \%$, enquanto aqueles em Campinas estiveram ao redor de $11,8 \%$. Diferenças semeIhantes foram também notadas por MAEDA et alii (1987) quando armazenaram sementes de cultivares de milho em Campinas e em Pariquera-Açu, região de clima semelhante ao de Ubatuba.

As diferenças nos teores de umidade entre as sementes das duas espécies foram pequenas; as de arroz atingiram, nas mesmas condições, em geral, valores ligeiramente mais altos.

O saco de plástico liso foi a única embalagem a restringir a passagem de vapor de água do ambiente para a semente, cujos teores finais de umidade estiveram apenas um pouco acima dos iniciais. Essa pequena diferença foi, provavelmente, devida mais à abertura e fechamento dos sacos durante a retirada de amostras das sementes, por ocasião dos testes, do que à passagem de vapor de água pelas paredes da embalagem.

Praticamente, não ocorreram diferenças entre os sacos de pano, papel e plástico trançado $5 \times 5$ e $5 \times 6$ quanto aos conteúdos de umidade, nos diversos períodos.

Os resultados dos testes periódicos de germinação e vigor encontram-se nos quadros 3 e 4 para sementes de arroz e milho respectivamente. Em ambas as espécies, as sementes armazenadas em Ubatuba deterioraram-se mais rapidamente, sobretudo quando acondicionadas nas embalagens permeáveis ao vapor de água. Em Campinas, as sementes de arroz embaladas em sacos de pano mantiveram germinação acima de $80 \%$ até os quinze meses, enquanto aquelas de Ubatuba o fizeram só até os seis meses. Em milho, essa diferença foi ainda mais marcante, pois as sementes acondicionadas nas embalagens permeáveis apresentaram germinação superior a $80 \%$ até os 24 meses, enquanto as de Ubatuba mantiveram aquele nivel só até os três meses. Resultados semelhantes aos de Campinas foram verificados por MAEDA et alii (1979) quando armazenaram sementes do milho híbrido 'IAC Hmd 6999-B', em Campinas, por 25 meses. 


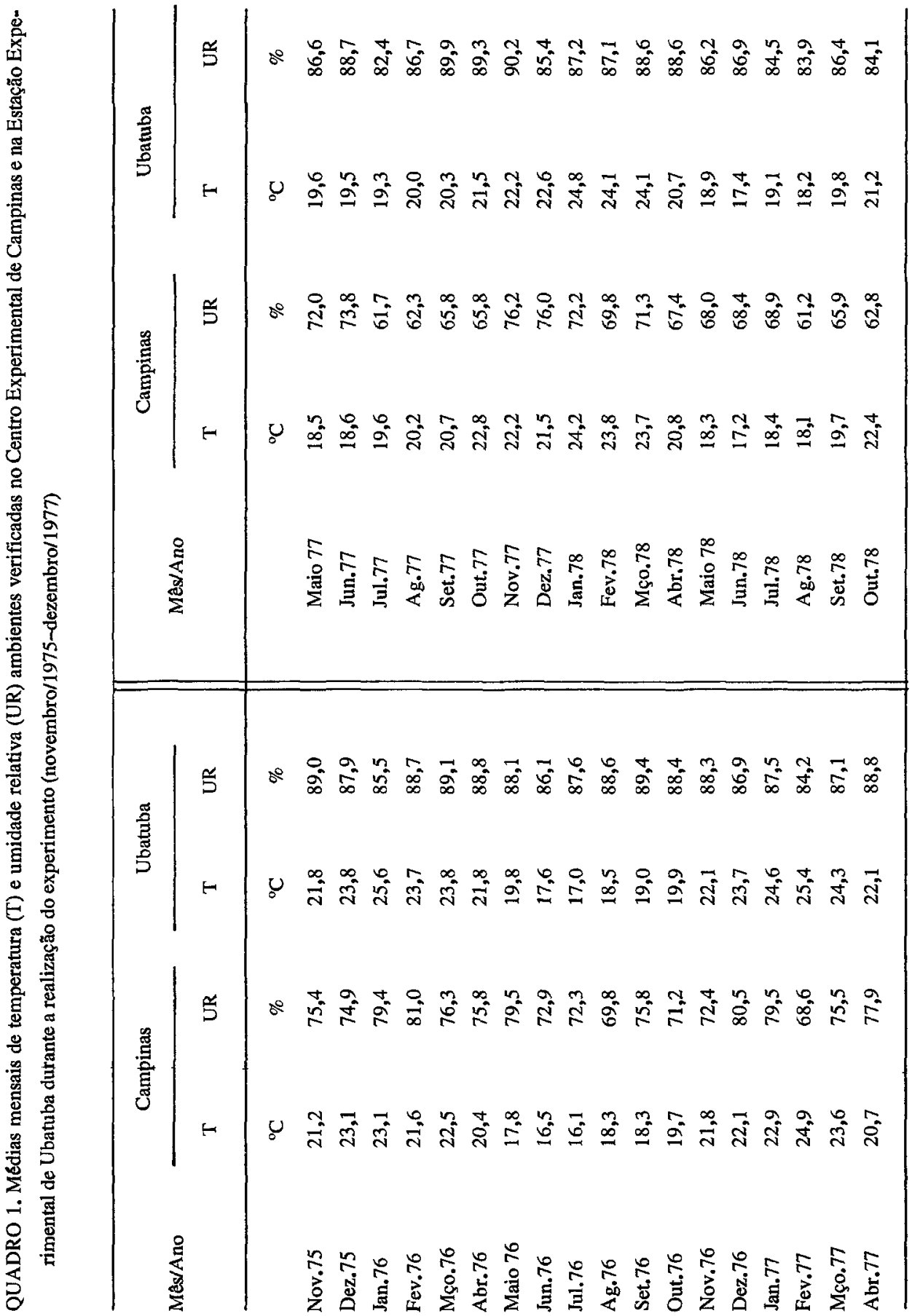




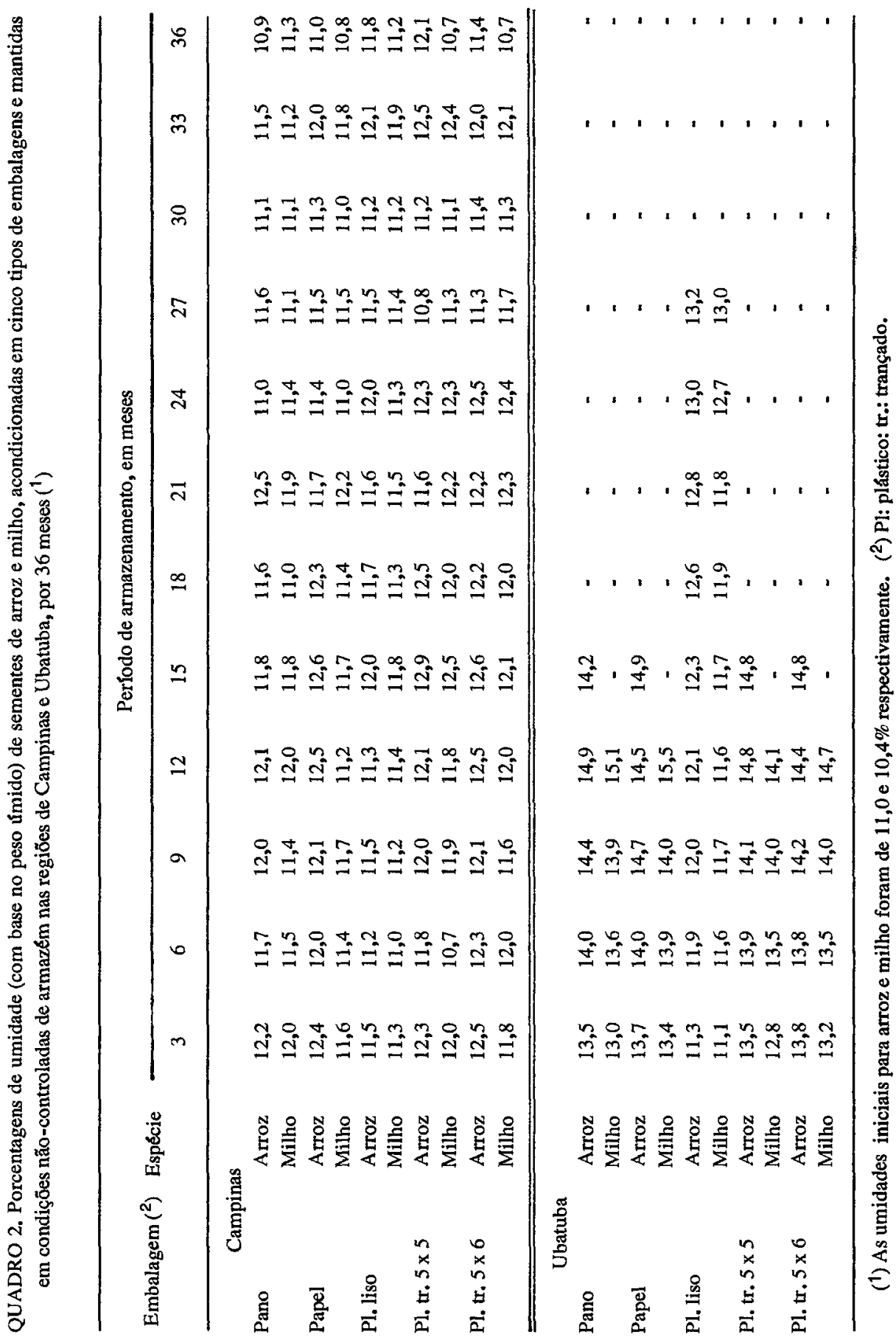




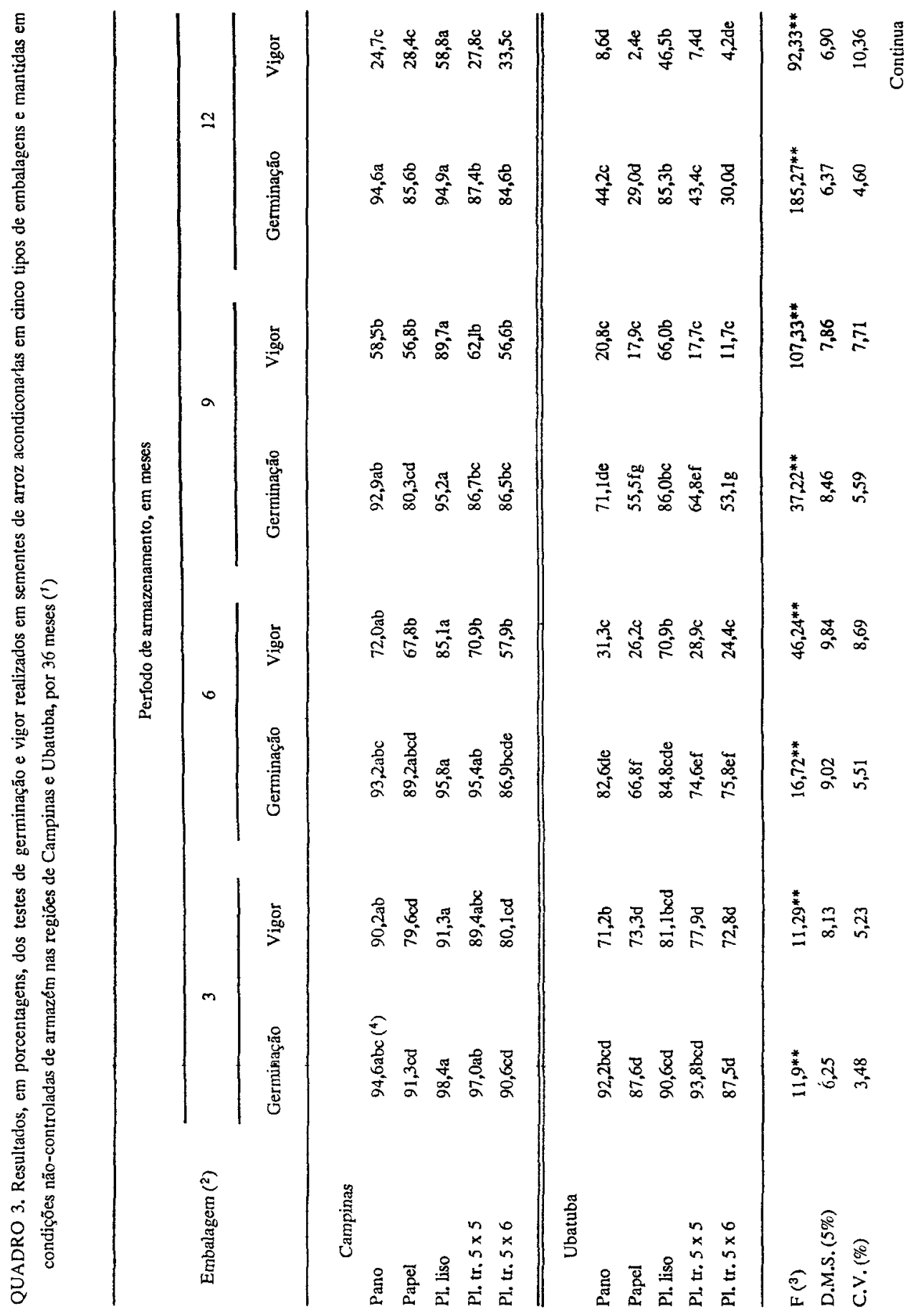




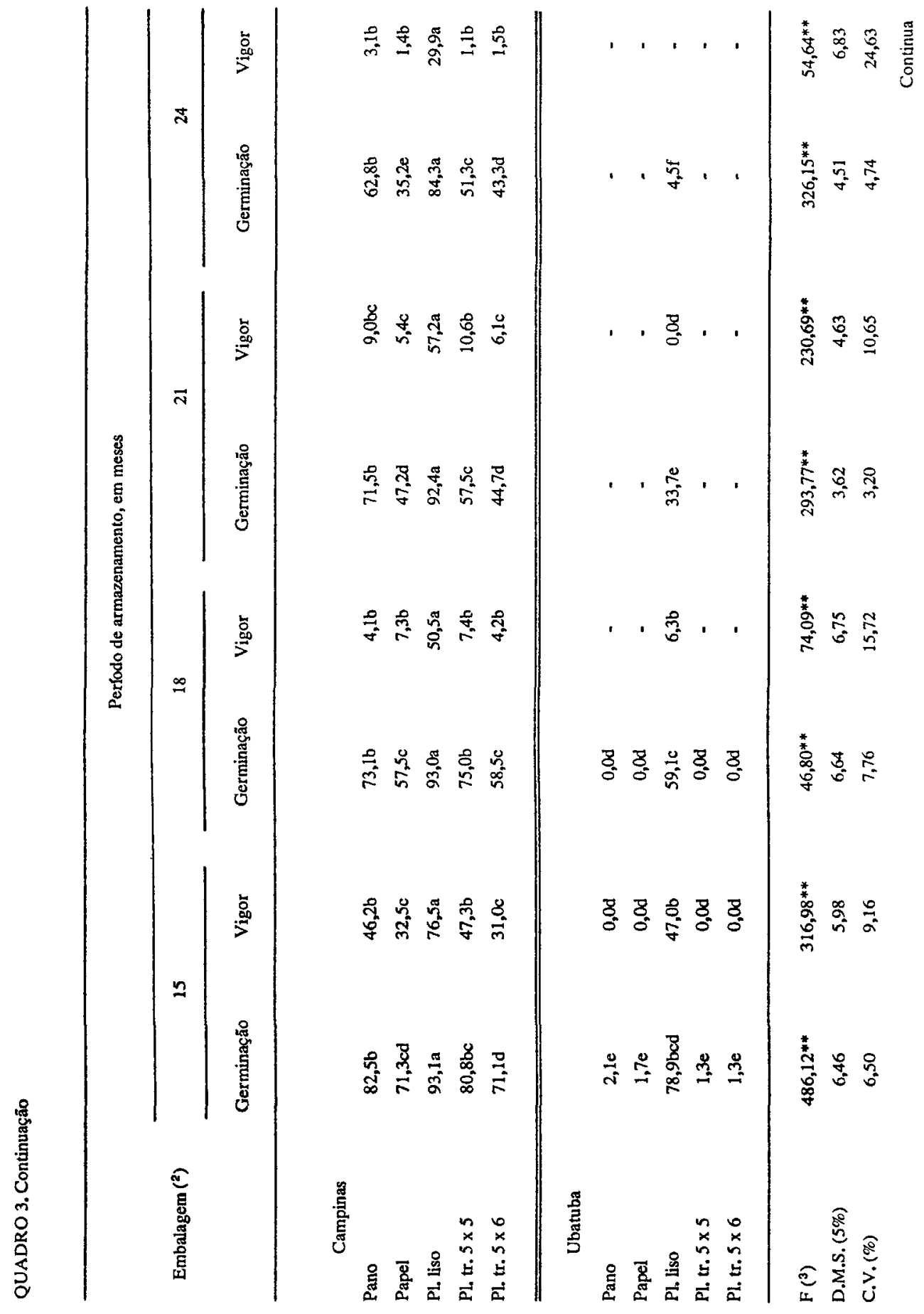




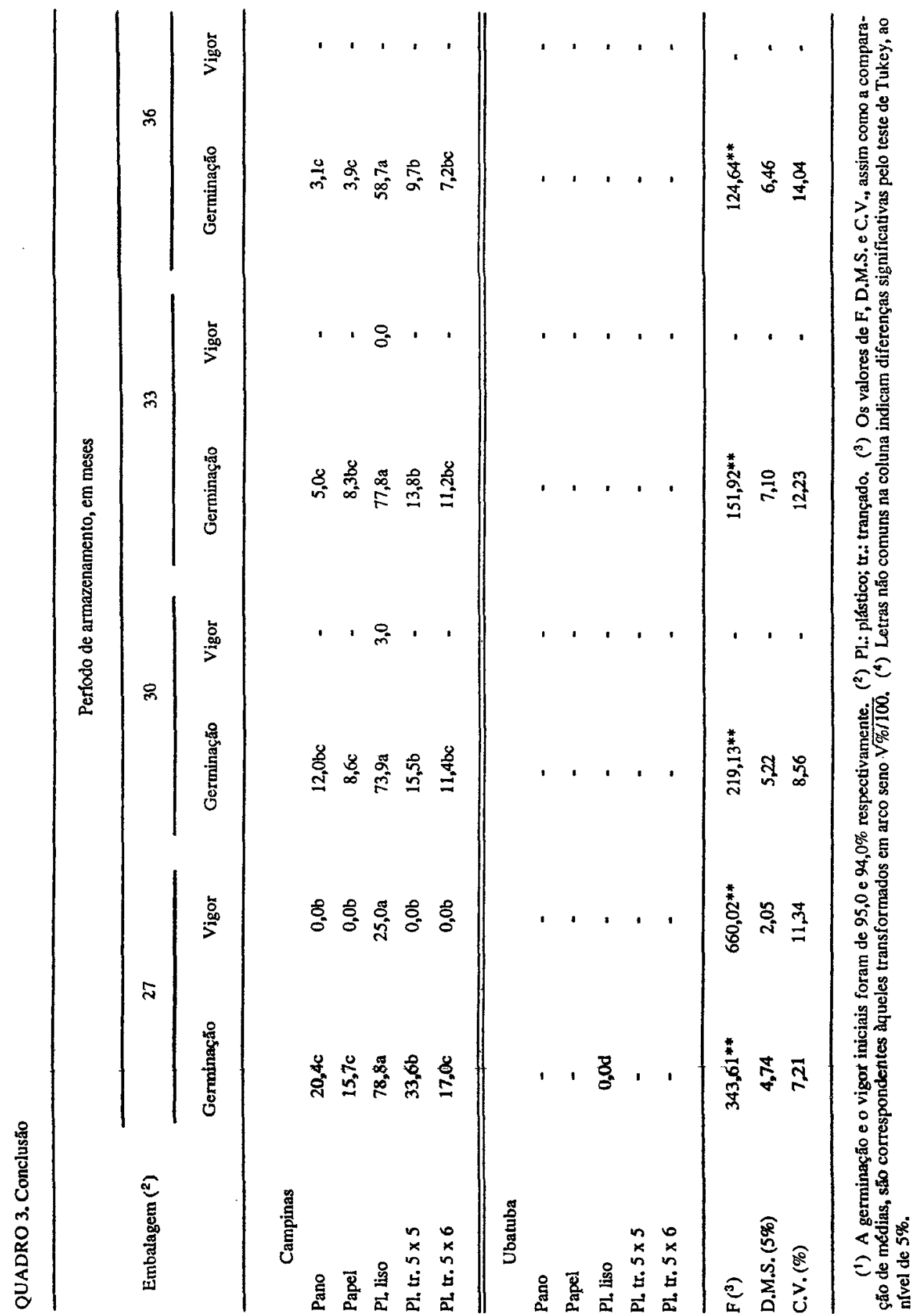




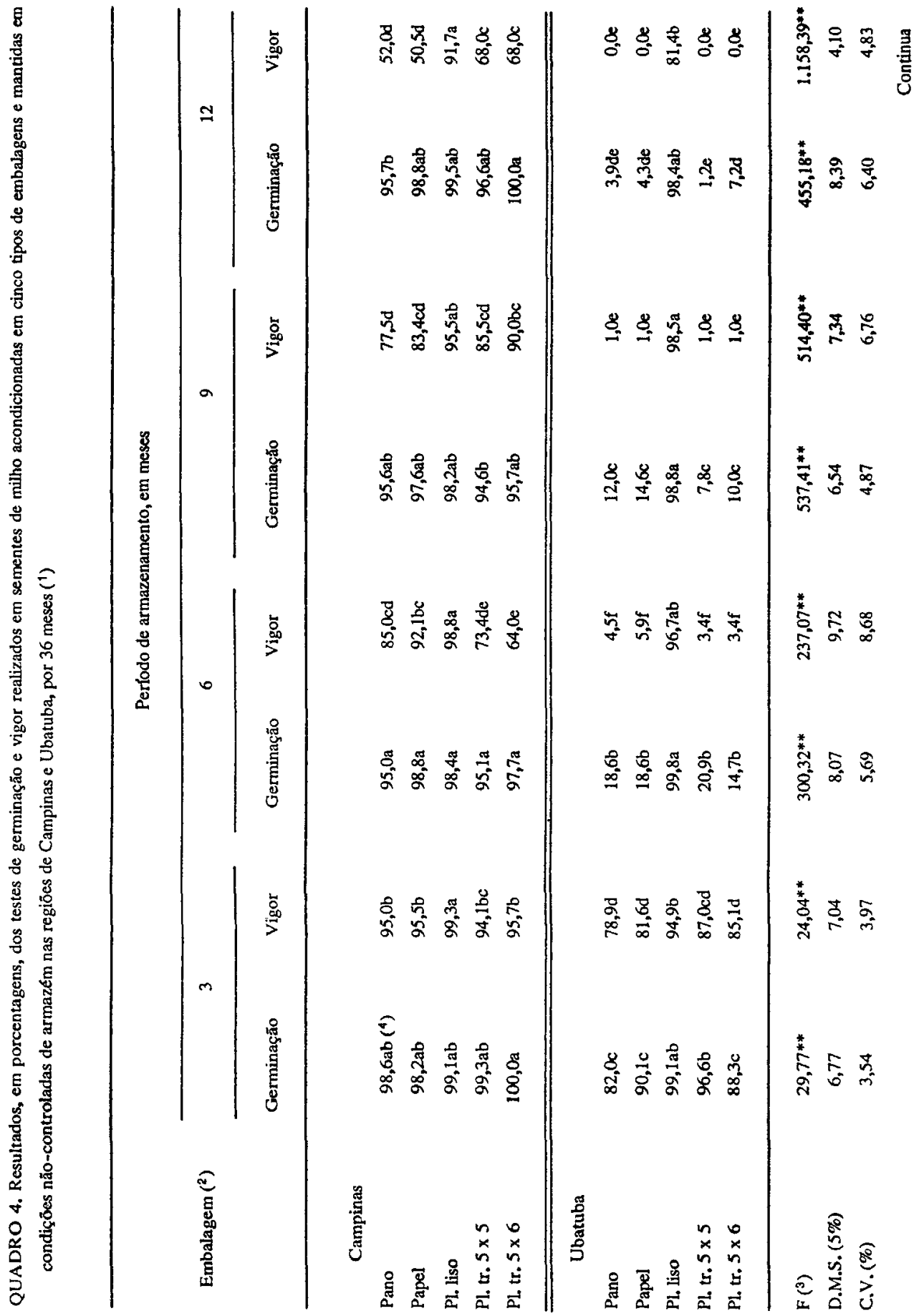




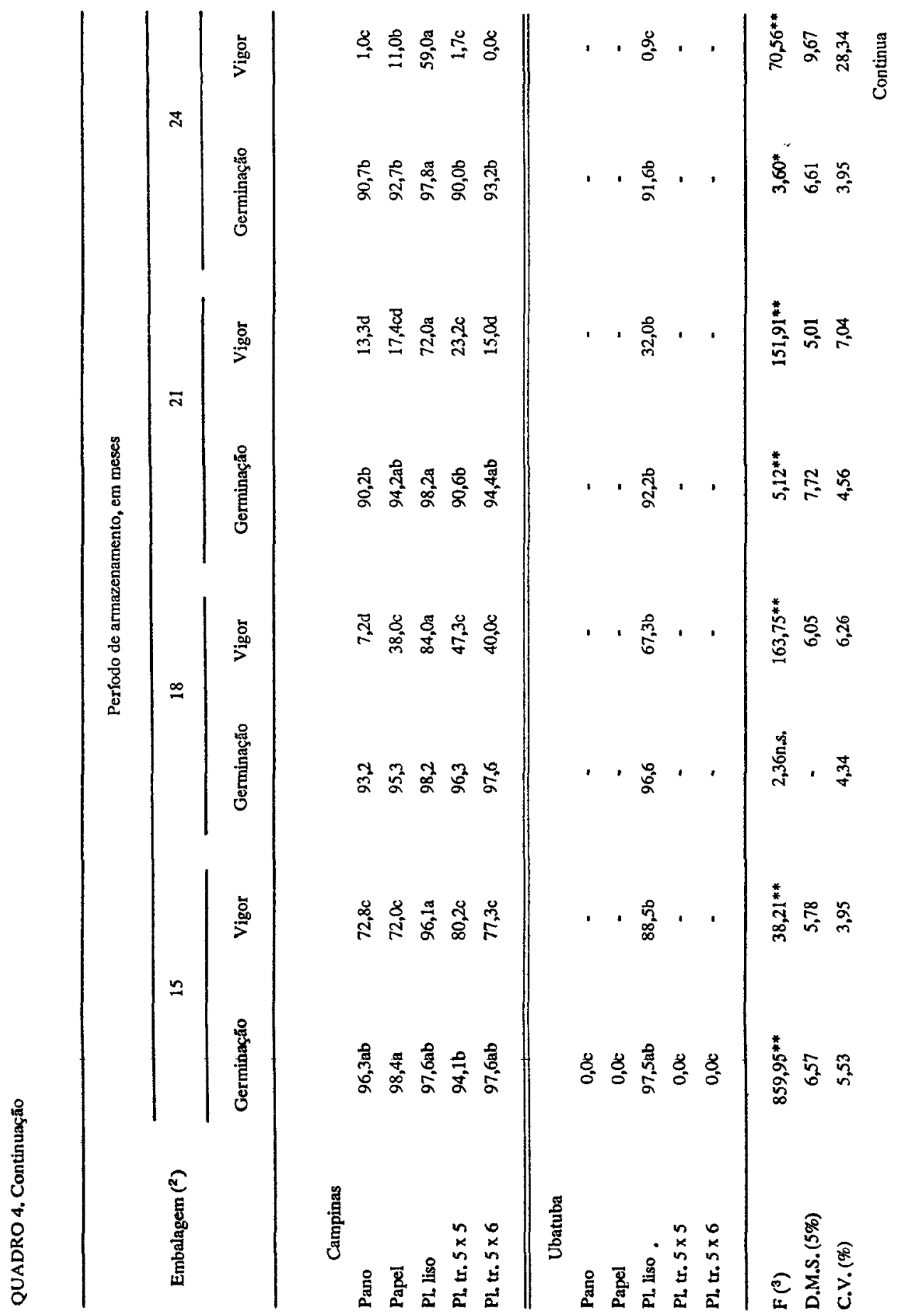




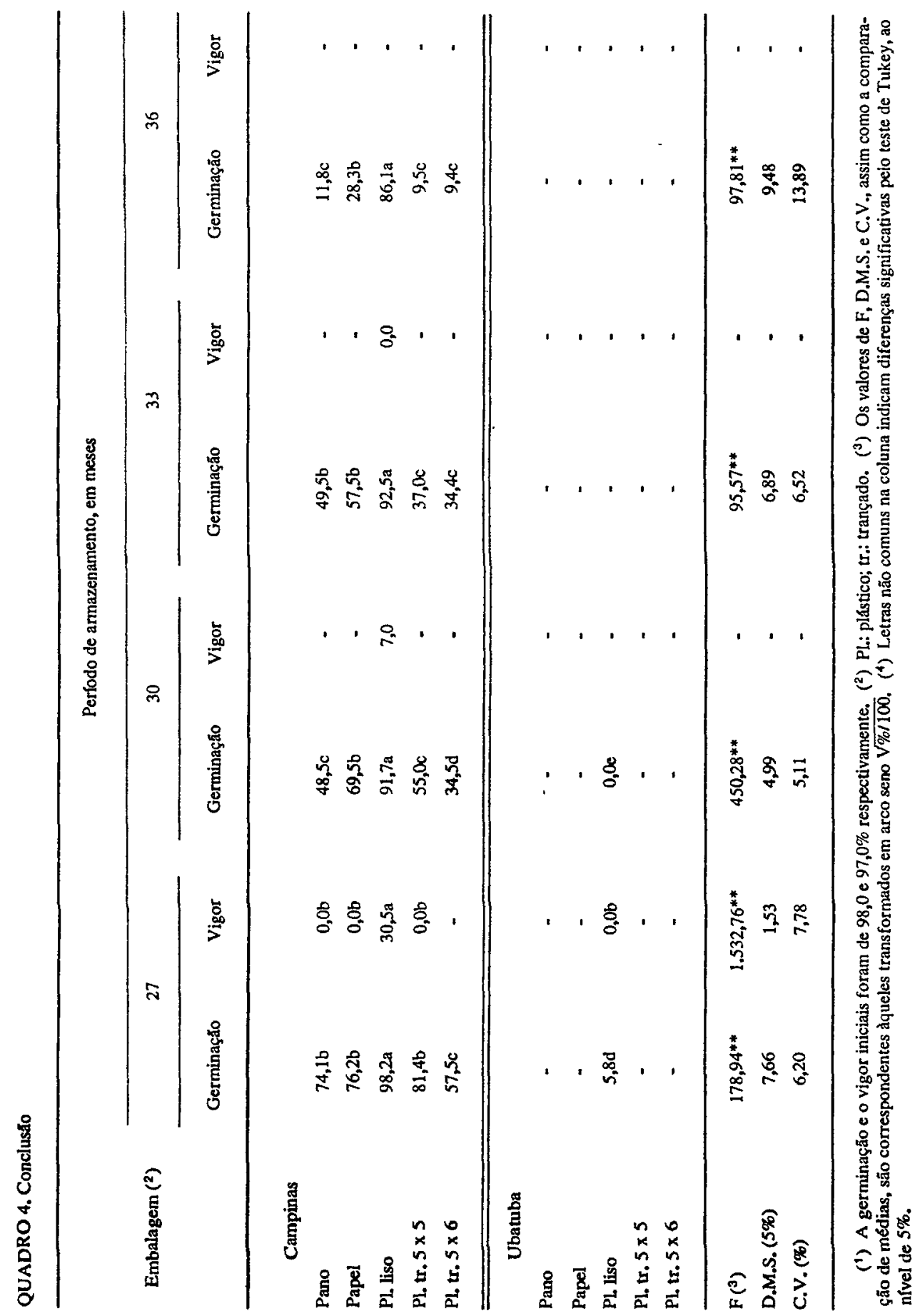


Os resultados obtidos em Ubatuba salientaram a grande dificuldade, ou mesmo impossibilidade, do armazenamento de sementes em condições não controladas em áreas quentes e úmidas do litoral paulista e, por extensão, em regiōes brasileiras de clima semelhante, como a Amazônia. Assim, na ausência de algum tipo de controle das condições ambientes do armazém, ou de acondicionamento especial das sementes, os agricultores de tais áreas podem ver-se obrigados a adquirir sementes de outras regiōes do país.

Em milho mantido em Campinas, não ocorreram diferenças de ordem prática entre a germinação das sementes embaladas em saco plástico liso e a daquelas nos outros tipos de embalagens, até os dezoíto meses; daí em diante, os valores de germinação e principalmente de vigor das primeiras foram, na maioria dos casos, estatisticamente superiores aos das segundas. Aos 36 meses, as sementes acondicionadas em saco plástico liso apresentaram ainda porcentagem de germinação relativamente alta, 86,1, enquanto aquelas nas embalagens de pano, papel, plástico trançado $5 \times 5$ e $5 \times 6$ exibiram, no mesmo período, porcentagens muito baixas: $11,8,28,3,9,5$ e 9,4 respectivamente.

Com relação às sementes de arroz, também armazenadas em Campinas, a superioridade do saco plástico liso tornou-se bastante clara a partir dos doze meses. Aos 36 meses, as sementes na embalagem de plástico liso exibiram a porcentagem de germinação de 58,7 , e as de pano, papel, plástico trançado $5 \times 5$ e $5 \times 6$, de $3,1,3,9,9,7$ e 7,2 respectivamente.

Em Ubatuba, para ambas as espécies, notadamente em milho, a vantagem do saco plástico liso foi ainda mais evidente. Assim, já aos quinze meses, a germinação das sementes de milho mantidas nas outras embalagens foi nula, enquanto aquelas mantidas no saco plástico liso exibiam ainda germinação bastante alta, $97,5 \%$.

Como se depreende, uma das alternativas para o armazenamento de sementes de arroz e milho em regiōes quentes e úmidas é sua secagem em niveis relativamente baixos de umidade $(10-11 \%$ ou menos) seguida de acondicionamento em saco plástico liso grosso $(0,25 \mathrm{~mm}$ de espessura), como o do presente experimento.

Para ambas as espécies e regiões, não ocorreram diferenças consistentes entre as sementes acondicionadas nas diversas embalagens, à exceção do plástico liso. Na maior parte dos períodos, não houve diferenças estatísticas entre elas, não só com relação à germinação como também ao vigor. Tais embalagens são bastante práticas para o acondicionamento de sementes armazenadas em regiōes menos hostis à manutenção da sua viabilidade, como o planalto paulista e o Sul do Brasil.

Em todos os casos, com o decorrer dos 36 meses de armazenamento, o vigor decresceu mais rapidamente que a germinação, como tem sido amplamente provado e explicado por inúmeros pesquisadores, entre os quais DELOUCHE \& 
BASKIN (1973). Um exemplo ilustrativo desse aspecto da fisiologia de sementes foi o do milho embalado em plástico liso e armazenado em Campinas que, embora apresentasse, de início, valores de germinação e vigor praticamente idênticos, exibiu, aos 33 meses, germinação alta, $92,5 \%$, e vigor de $0 \%$.

\title{
SUMMARY
}

\section{STORAGE OF RICE AND CORN SEEDS IN DIFFERENT CONTAINERS AND LOCALITIES OF THE STATE OF SÃO PAULO, BRAZIL}

\begin{abstract}
Seeds of 'IAC 1246' rice (Oryza sativa L.) and 'Hmd 7974' hybrid corn (Zea mays L.) were packed in water vapor permeable containers as cloth bag, paper bag $5 \times 5$ and $5 \times 6$ woven plastic bag; and in a $0.25 \mathrm{~mm}$ thick moisture-resistant plastic bag. The seeds were then maintained under non-controlled room temperature conditions in the localities of Campinas and Ubatuba, both in the State of São Paulo, and tested for moisture content at every three month interval for a period of 36 months. The seeds stored at Ubatuba deteriorated faster than those stored at Campinas, mainly $w$ hen packed in water vapor permeable containers. For example, at Campinas, rice seeds held in cloth bags maintained seed germination higher than $80 \%$ up to 15 months, while those at Ubatuba did so only up to 6 months. Packing seeds in $0.25 \mathrm{~mm}$ thick plastic films was advantageous, mainly at Ubatuba where the germination of the corn seeds, for example, was null after 15 months when held in the other containers, and $97.5 \%$ when held in the plastic films. The packages made with cloth, paper, and $5 \times 5$ and $5 \times 6$ woven plastic gave similar results for the preservation of seed germination and vigor. This indicated the great difficulty, or even the impossibility of storing seeds in warm and humid areas, like Ubatuba, unless the storage temperature and/or relative humidity are controlled, or seed moisture is reduced to relatively low levels (10-11\% or less) and seeds are packed in a moisture-resistant container. The water vapor permeable containers showed to be adequate to mantain seed viability and vigor in regions with more favorable climate.
\end{abstract}

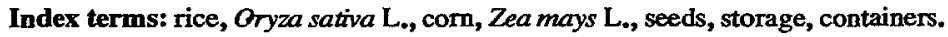

\section{REFERÊNCIAS BIBLIOGRÁFICAS}

BACCHI, O. \& ZINK, E. Expurgo de sementes de milho com brometo de metila em diferentes doses e tempos de exposição. Bragantia, Campinas, 21:CXXXIII-CXL, 1962. (Nota, 23)

BRASIL. Ministério da Agricultura. Divisāo de Sementes e Mudas. Regras para análise de sementes. Brasilia, 1980. 188p.

DANIELSON, C.B. Storage and packaging. In: PROCEEDINGS SHORT COURSE FOR SEEDSMEN. State College, Mississippi State University, 1962. p.135-137. 
DELOUCHE, J.C. Metodologia de pesquisa em sementes. II. Secagem, beneficiamento e armazenamento. Revista Brasileira de Sementes, Brasília, 3(2):48-55, 1981.

- Precepts for seed storage. In: PROCEEDINGS SHORT COURSE FOR SEEDSMEN. State College, Mississippi State University, 1968. p.85-119.

\& BASKIN, C.C. Accelarated aging techniques for predicting the relative storability of seed lots. Seed Science \& Technology, 1:427-452, 1973.

-; MATTHES, R.K.; DOUGHERTY, G.M. \& BOYD, A.H. Storage of seed in subtropical and tropical regions. "Seed Science and Technology, 1:671-700, 1973.

FONSECA, J.R.; FREIRE, A.B.; FREIRE, M.S. \& ZIMMERMANN, F.J.P. Conservação de sementes de arroz sob três sistemas de armazenamento. Revista Brasileira de Sementes, Brasilia, 1(3):71-76, 1979.

HAGGERTY JUNIOR, N.J. Packaging. In: PROCEEDINGS SHORT COURSE FOR SEEDSMEN. State College, Mississippi State University, 1960. 139-145.

HARRINGTON, J.F. Packaging seed for storage and shipment. Seed Science and Technology, 1:701-709, 1973.

- Problems of seed storage. In: HEYDECKER, W., ed. Seed ecology. University Park and London, The Pennsylvania State University Press, 1972. p.251-263.

HELMER, J.D. Basic considerations of seed storage. In: PROCEEDINGS SHORT COURSE FOR SEEDSMEN. State College, Mississippi State University, 1965. p.141-143.

JUSTICE, O.L. \& BASS, L.N. Principles and practices of seed storage. Washington, U.S.D.A., 1978. 289p. (Agriculture Handbook, 506)

MAEDA, J.A.; LAGO, A.A.; MIRANDA, L.T. \& TELLA, R. Armazenamento de sementes de cultivares de milho e sorgo com resistências ambientais diferentes. Pesquisa Agropecuária Brasileira, Brasília, 22(1):1-7, 1987.

- ; SA WAZAKI, E. \& POMMER, C.V. Influência da adubação mineral NPK sobre a qualidade da semente de milho. Bragantia, Campinas, 38:165-174, 1979.

MORA, M.A.C. \& ECHANDI, R.Z. Evaluación del efecto de condiciones de almacenamiento sobre la calidad de semillas de arroz (Oryza sativa L.) y de maíz (Zea mays L.). Turrialba, Costa Rica, 26:113-416, 1976.

RESENHAS meteorológicas. O Agronômico, Campinas, 27/28:401-448, 1975/76; 29/30:311-336, 1977/78, 31:167-178, 1979.

TOSELLO, J.; ORTOLANI, D.B. \& MASCHIETTO, J.C. Observações sobre a conservação de sementes. In: SEMINÁRIO BRASILEIRO DE SEMENTES, 2., Pelotas, 1968. Anais. p.323-332. 